استخلاص و تنقية الانزيم Deoxyribonuclease I من البنكرياس البقري

\title{
Extraction and purification of bovine pancreatic Deoxyribonuclease I
}

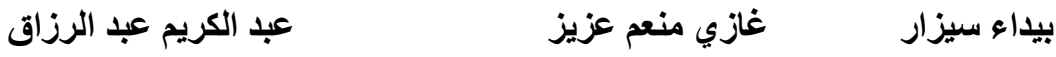

$$
\begin{aligned}
& \text { قسم النقنيات الاحيائية /كلية العوم / جامعة بغاد }
\end{aligned}
$$

Baidaa S. Hermiz Ghazi M. Aziz Abdel kareem A. Alkazaz

Dept of Biology/ College of Science/ University of Baghdad

المستخلص : :

جُمِعَت عينات من البنكرياس البقري والغدة الزعترية للعجول من المجازر المحلية لاستخلاص

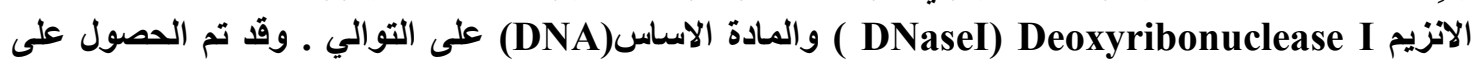

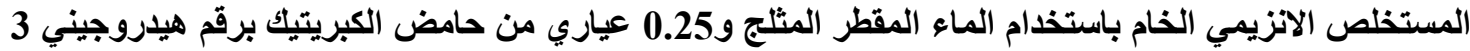

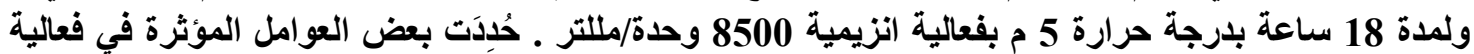

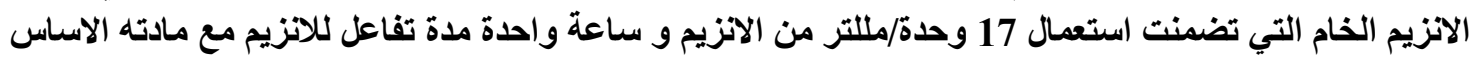

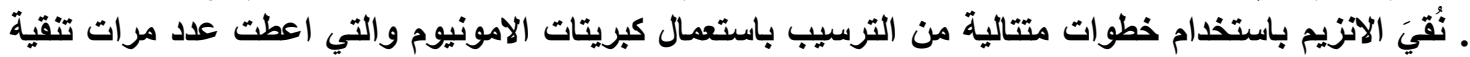
مقدارها 529.4 بحصيلة انزيمية 6.35 \%٪ اتصف الانزيم المنقى جزئيا بكونه فعالاً عند تركيز 2.7 وحدة / مللتر و50 مايكروغرام / مللترمن DNA الغدة الزعترية بعد 30 دقيقة من زمن التفاعل وامتلك الانزيم ثباتاًعند رقم

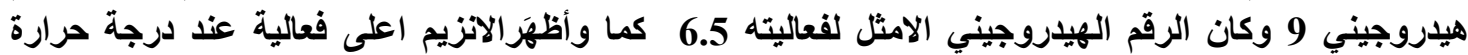

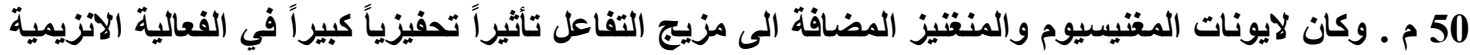

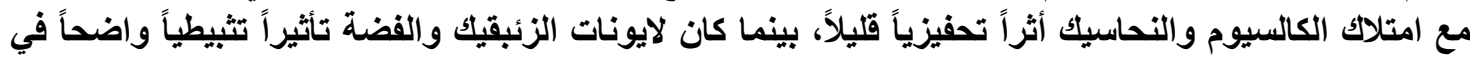
فعالية الانزيم ـ ثبطت فعالية الانزيم بوجود بعض العوامل المدنترة للبروتين والتي منها SDS) Sodium dodecyl sulphate كاملة عند معاملته ببعض العوامل المختزلة مثل 2- مركبتوايثانول واليوريا مع احتفاظ الانزيم بفعاليته عند وجود مادة3 (PMSF) Phenyl methyl sulphonyl floride

\section{Abstract}

amples of bovine pancreatic and calf thymus glands were collected from local 2 slaughterers to extract deoxyribonuclease I enzyme (DNase I) and DNA respectively. Crude extract was prepared by using cooled distilled water and $0.25 \mathrm{~N}$ sulfuric acid .This study show that the best condition for the crude extract activity was $17 \mathrm{U} / \mathrm{ml}$ and $1 \mathrm{hr}$. Incubated period reaction with its substrate.The bovine pancreatic DNase I was purified by several steps of precipitation using ammonium sulphate to 529.4 times, with an enzymes yield $6.35 \%$. Enzyme characterization studies indicate that: it is active at $2.7 \mathrm{U} / \mathrm{ml}$, and $50 \mu \mathrm{g} / \mathrm{ml}$ DNA after $30 \mathrm{~min}$ of reaction time, the enzyme activity was higher at pH 6.5 and it showed stability at pH 9. The maximum enzyme activity was reported at $50^{\circ} \mathrm{C}$ The results obtained from the role of metal ions $\left(\mathrm{Mg}^{+2}, \mathrm{Mn}^{+2}\right)$ on enzyme activity indicate that these ions stimulated the enzyme activity while the $\mathrm{Ca}^{+2}$ and $\mathrm{Cu}^{+2}$ had lower stimulating activity on the enzyme but $\mathrm{Ag}^{+1}$ and $\mathrm{Hg}^{+2}$ showed inhibitory effect on enzyme activity. In addition the enzyme activity was inhibited by using denaturing Sodium dodecyl sulphate (SDS), chelating agents Ethylene diamine tetra acetic acid (EDTA), 
and reducing agents (2-Merceptoethanol and Urea), and maintained it's activity when incubated with Phenyl Methyl Sulphonyl Floride (PMSF).

المقدمة

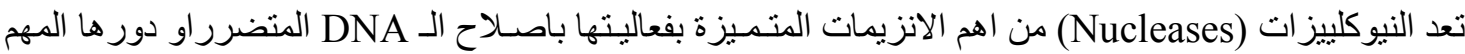

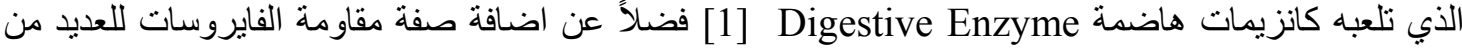
النباتات، حيث ثُعَد انزيمات النيوكلييزات المحلة للمادة الور اثية DNA أو RNA العائدة للفايروسات من الطر ائق

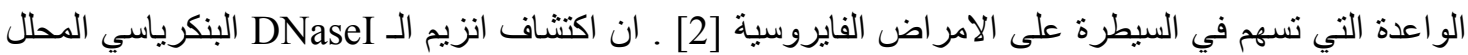

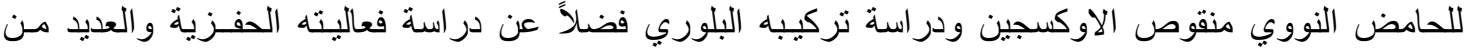

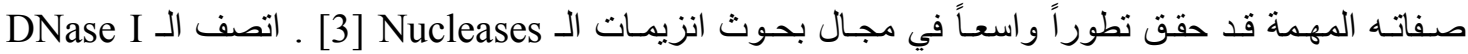

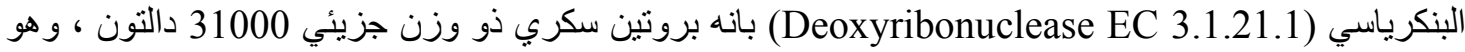

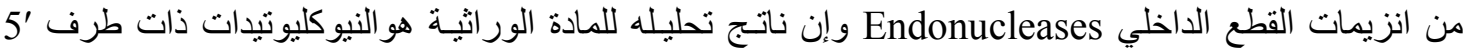

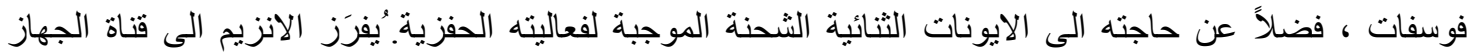

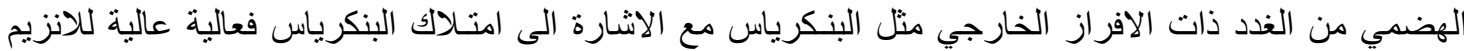

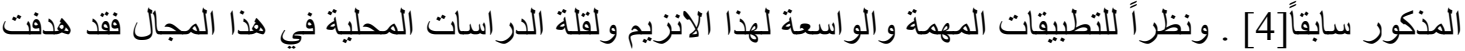

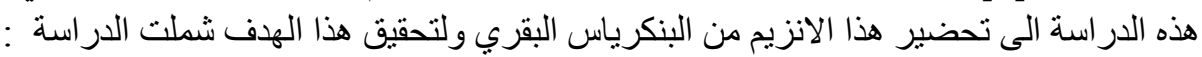

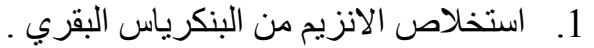

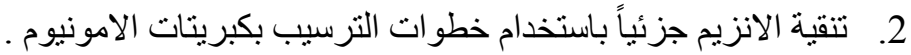
3. تحديد بعض العو امل المؤثرة في فعالية الانزيم المنقى جزئياً.

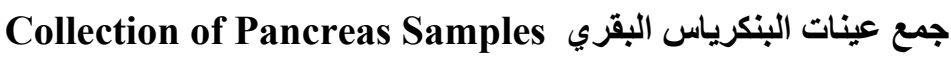
جُمعت عينات من بنكرياس الأبقار( 2.5 كغم ) من المجازر المحلية ، وبحالة طرية وطازجة وقد شخصت في

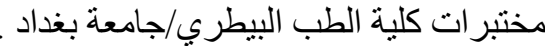

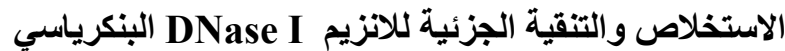

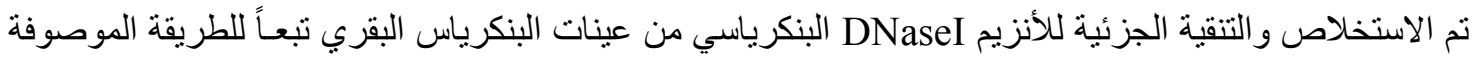

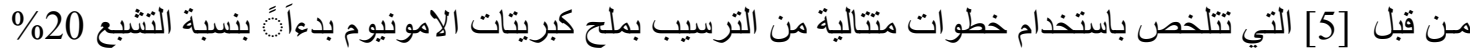

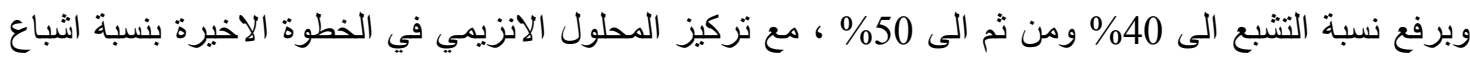

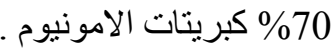

Extraction and Purification of Calf إستخلاص وتنقية المادة الاساس (دنا الغدة الزعترية للعجل) Thymus DNA

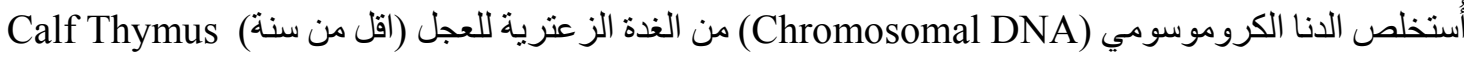

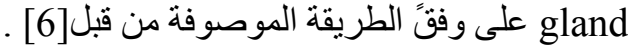
طرائق قياس فعالية الانزيم DNase I البنكية البنكرياسي

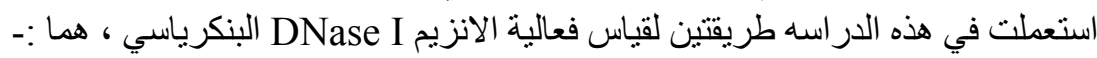

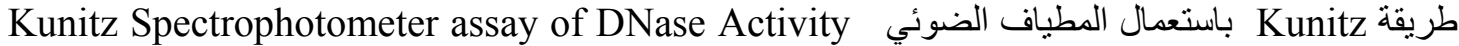

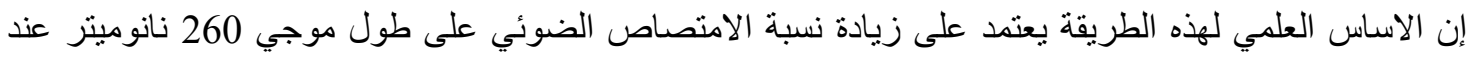

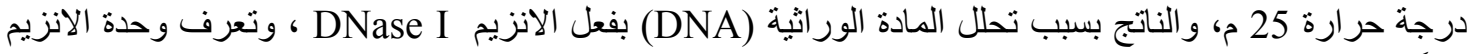
تبعاً لطريقة Kunitz بانها كمية الانزيم التي تسبب زيادة في الامتصاصية عند طول موجي 260 نانوميتر مقدارها

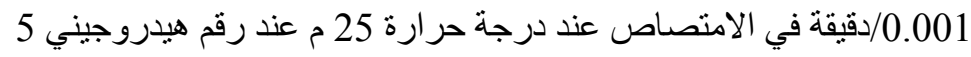


Gel assay of DNase I Activity طريقة الترحيل الكهربائي في هلام الاكاروز

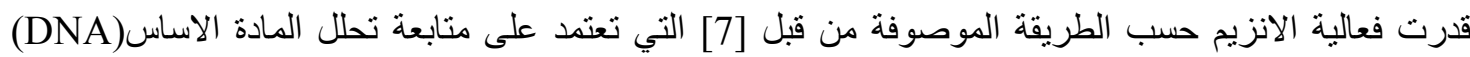
بتركيز 1 مايكرو غرام/مللتر بفعل الانزيم Nase I في مستخلصات البنكرياس البقري باستعمال الترحيل الكهربائي

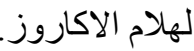
تقدير تركيز البروتين أُستخدمت الطريقة المطلقة (Absolute Method) لتقدير تركيز البروتين في نماذج الانزيم المستخلص و الموصوفة

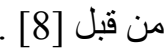
تحديد بعض العوامل المؤثرة على فعالية الانزيم الخام تحديد التركيز الامثل للانزيم الخام التوني

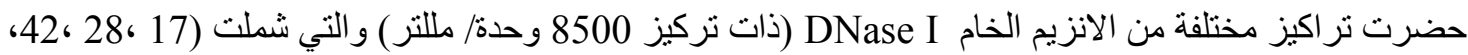

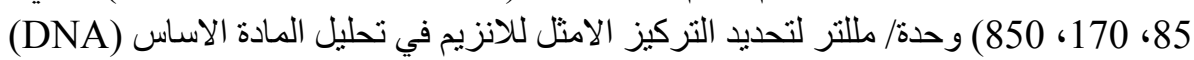
تحديد زمن التفاعل الامثل للانزيم الخام

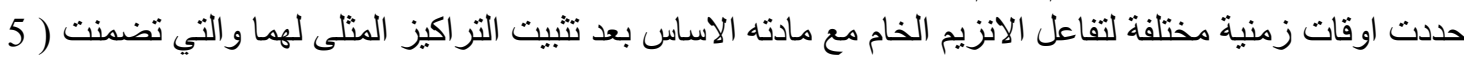

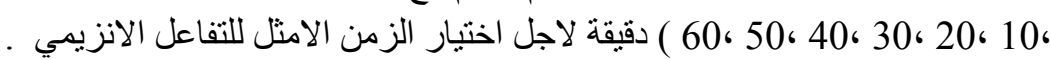

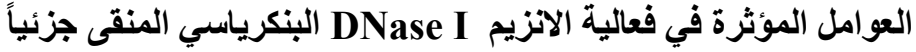
تعيين التركيز الامثل للمادة الاساس فئرة (DNA)

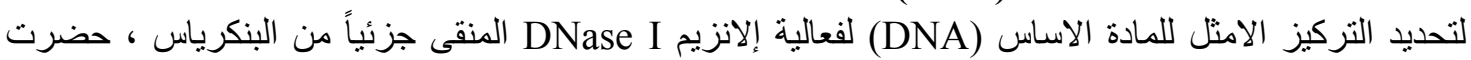

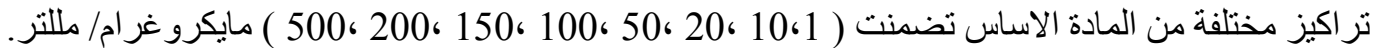

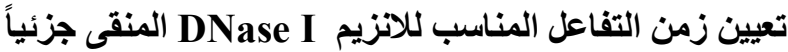

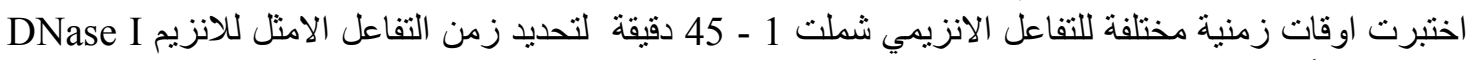
المنقى جزئياً. تعيين الرقم الهياروجيني الامثل لفعالية الانزيم

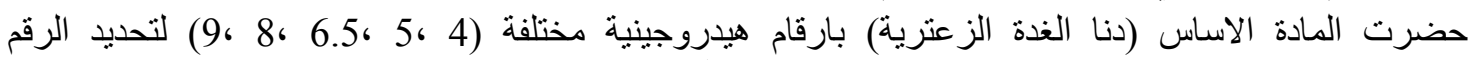

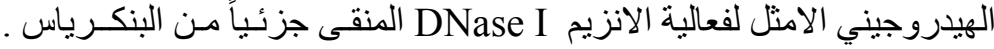
تحديد الرقم الهيدروجيني الامثل لثبات الانزيم

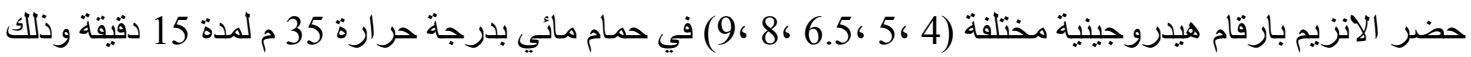

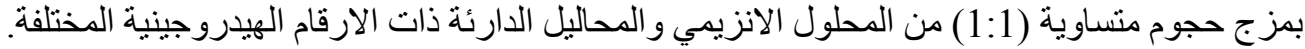

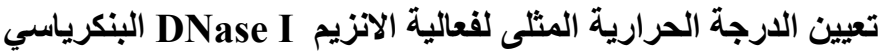
لتعيين الدرجة الحرارية المثلى لفعالية الانزيم

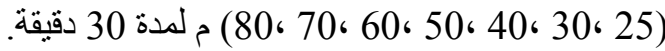
تأثير بعض الاملاح في فعالية الانزيم DNase I البنكرياسي

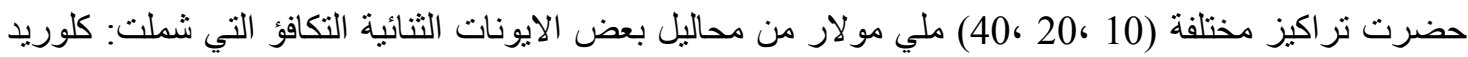

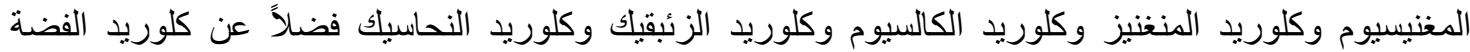

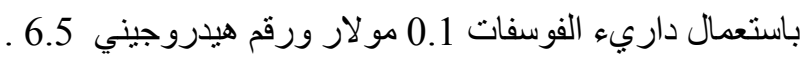
تأثير بعض المركبات الكيميائية على فعالية الانزيم

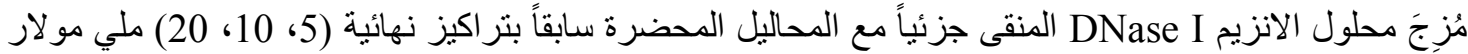

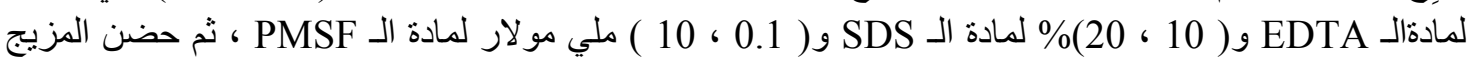
بدرجة حرارة 35 م لمدة 15 دقيقة . تأثير اليورياو 2- مركبتو ايثانول في فعالية الانزيم 
حُضِرَ محلول اليوريا 2- مركبتو ايثانول اعتماداً على الطريقة الموصوفة من قبل [9] .

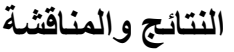

استخلاص المادة الاساس (دنا الغدة الزعترية للعجول)

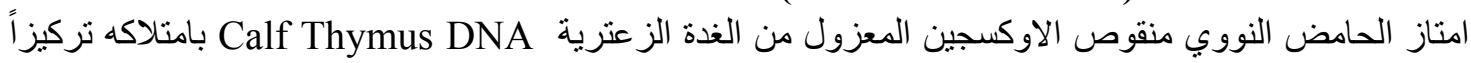

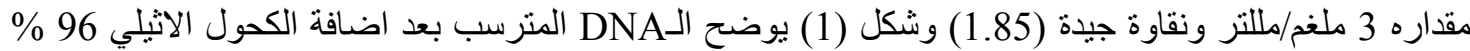

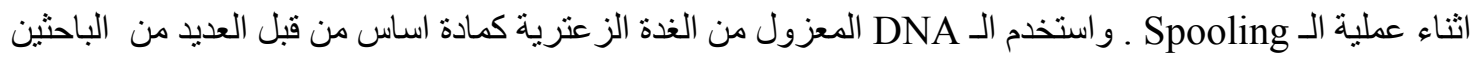
لقياس فعالية الانزيم DNase I البنكرياسي [ 10,5] .

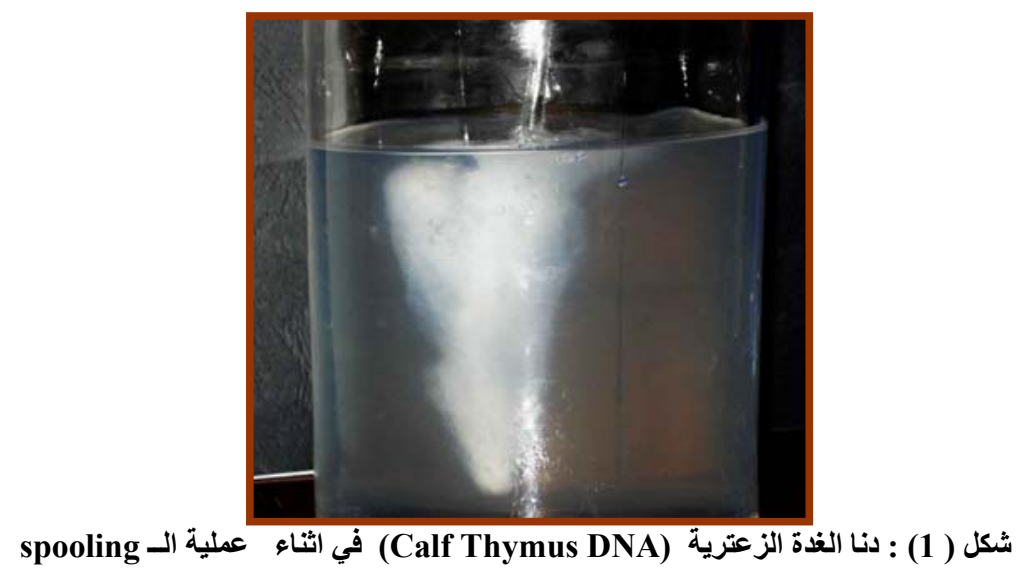

استخلاص الانزيم DNase I الخام من البنكرياس البقري

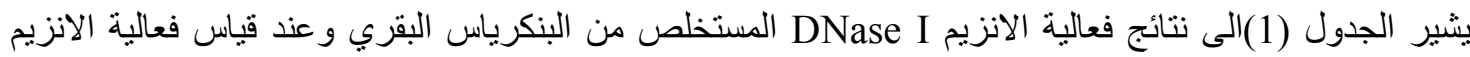

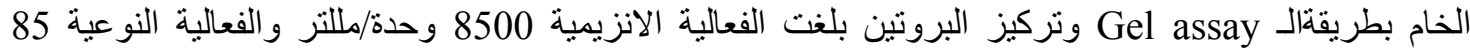

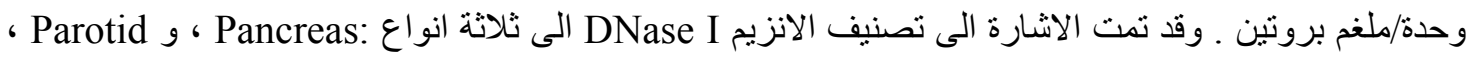

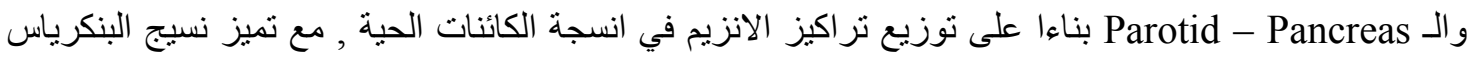

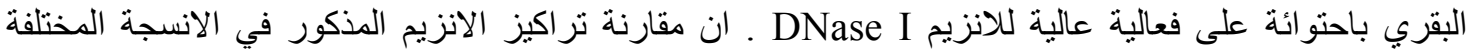

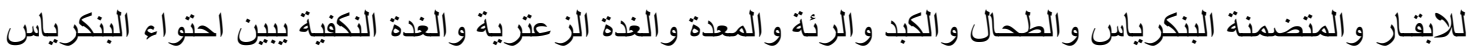

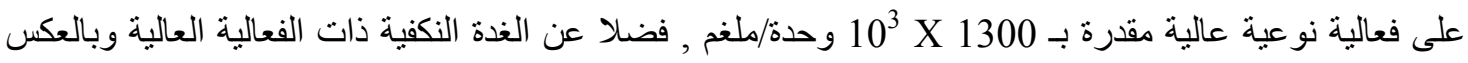

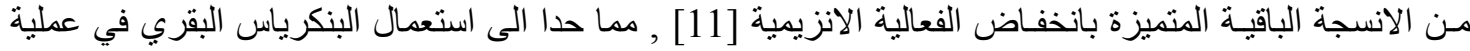

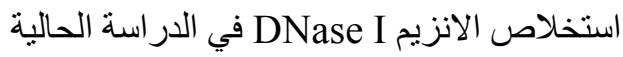
تحديد بعض العوامل المؤثرة في فعالية الانزيم الخام التركيز الامثل للانزيم الخام

لوحظ ان الانزيم DNaseI البنكرياسي الخام يمتلك القدرة على تحليل الـ DNA الـ

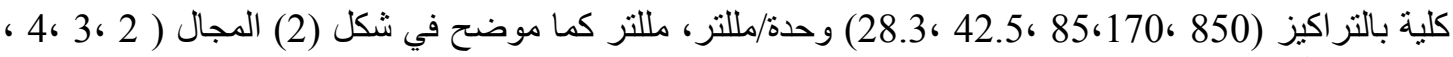

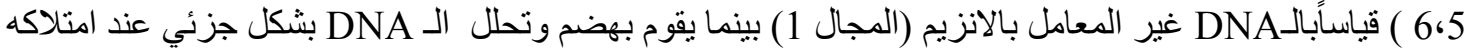

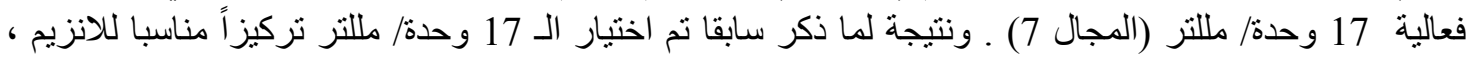

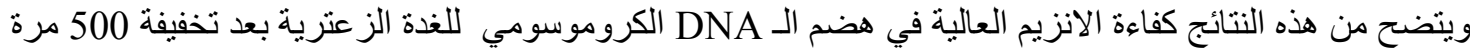

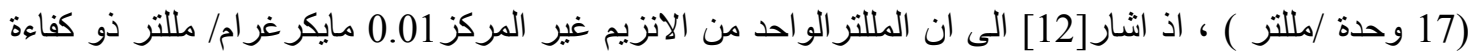

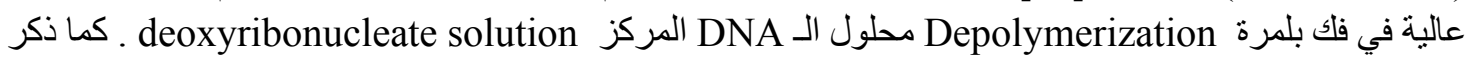
[13] ان الانزيم DNase II البنكرياسي يمنلاك فعالية عالية في تحلل المادة الاساس حتى بتركيز 0.3 وحدة /مللتر تحت ظروف التفاعل المنلى للانزيم المذكور . ل 
- المجال رقم (1) : نموذج الدنا بتركيز5 مايكروغرام /مليلتر غير معامل بلانزيم

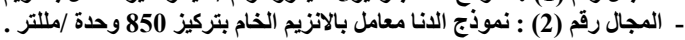

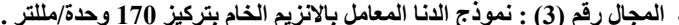

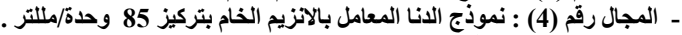

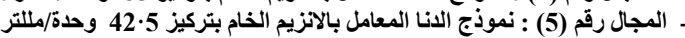

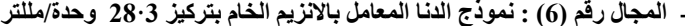

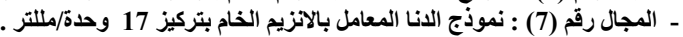

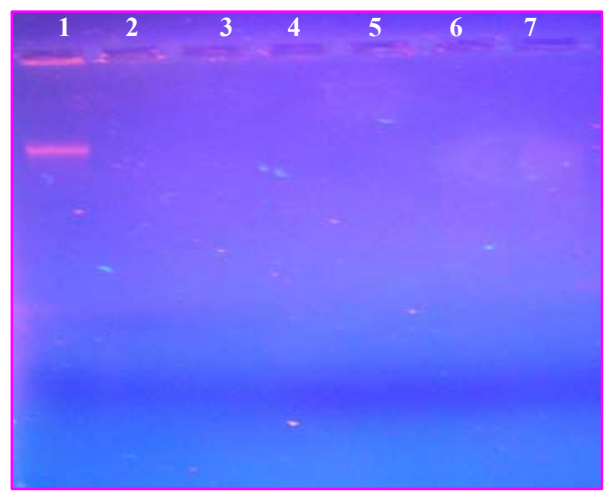

شكل (2 ) :الترحيل الكهربائي لنواتج تفاعل الانزيم مع المادة الاساس(دنا الغدة الزعترية) لتحديد التركيز

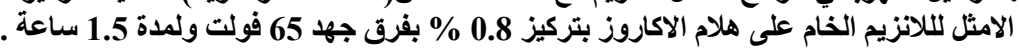

\section{زمن التفاعل الامثل للانزيم الخام}

اظهرت النتائج قدرة الانزيم الخام بفعالية 17 وحدة/مللتر على تحليل المادة الاساس بتركيز 5 مايكروغر ام/مللتر بعد الإن

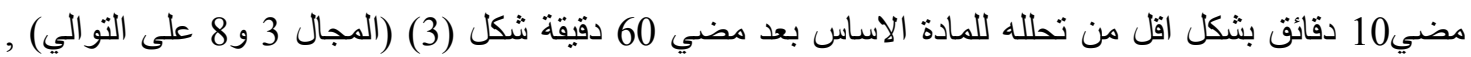

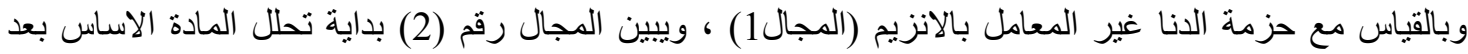

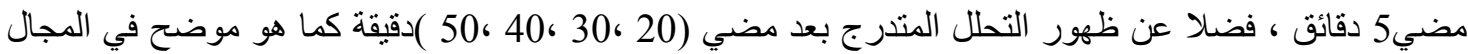

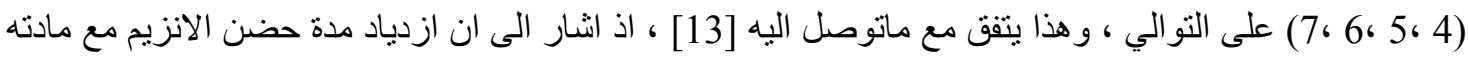

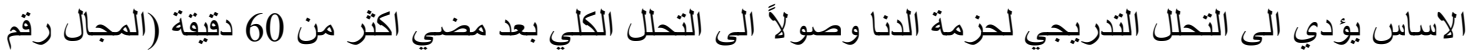

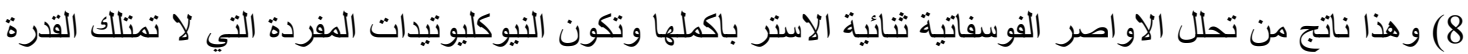

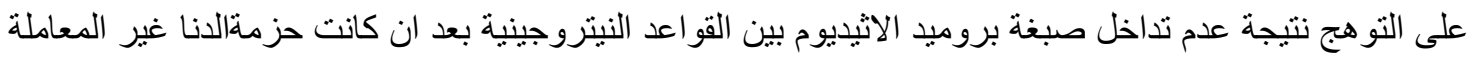

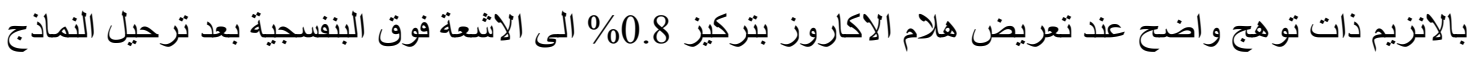
السابقة كهربائيا .

- المجال رقم (1) : نموذج الدنا بتركيز5 مايكروغرام/مليلتر غير معامل بالانزيم .

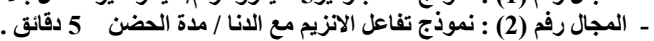

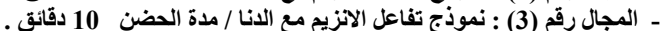

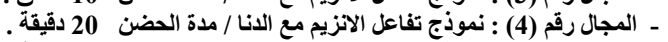

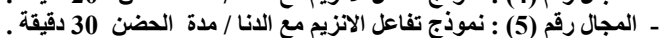

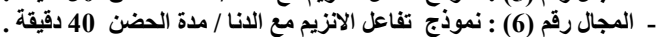

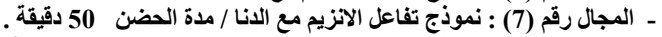

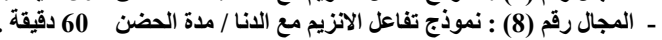

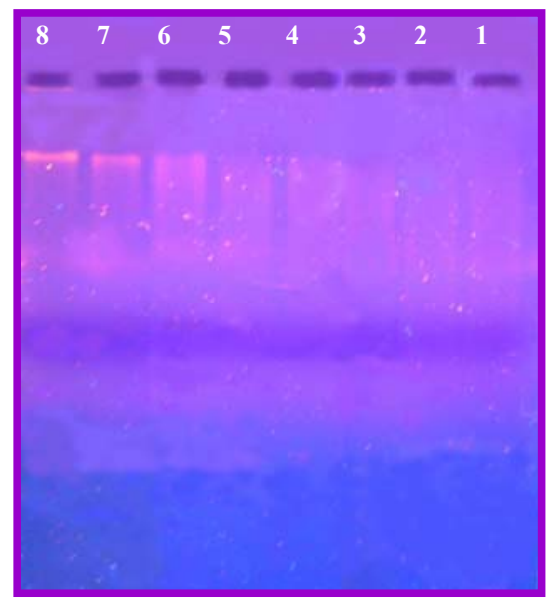

شكل (3 ): الترحيل الكهربائي لنواتج تفاعل الانزيم مع المادة الاساس(دنا الغدة الزعترية) باوقات حضن مختلفة على هلام الاكاروز

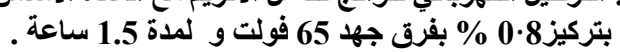


تنقية الانزيم DNase I البنكرياسي

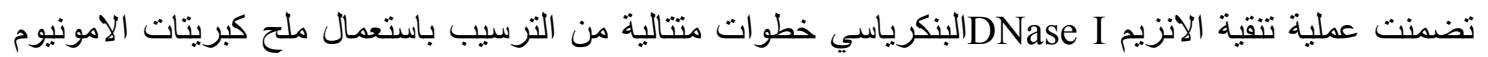
بنسب اشباع مختلفة، وعند متابعة قيم الفعالية النوعية للانزيم المذكور للمر احل المختلفة من هذه العملية كما مبين في الائي

\begin{tabular}{|c|c|c|c|c|c|c|c|}
\hline الحصيلة & عدد مرات & الفعالية الكلية & الفعالية النوعية & الفعالية & البرتين & الحجم & خطوات التنقية \\
\hline الاتزيمية \% & التنقية & $10^{5}$ x) & (وحشة"/ملفم)" & (وحدة/ملتلتر) & (ملف/مملتر) ) & (ملتزر) & \\
\hline 100 & 1 & 85 & 85 & 8500 & 100 & 1000 & $\begin{array}{c}\text { مستخلص خام (Crude Extract) } \\
\text { (Crude }\end{array}$ \\
\hline 14.88 & 12.9 & 12.65 & 1100 & 11000 & 10 & 115 & 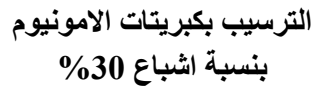 \\
\hline 12.7 & 16.2 & 10.8 & 1384.6 & 9000 & 6.5 & 120 & 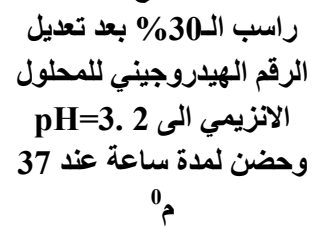 \\
\hline 6.35 & 529.4 & 5.4 & 45000 & 27000 & 0.6 & 20 & 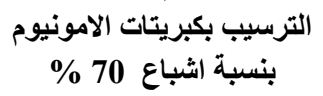 \\
\hline
\end{tabular}

يمكن ملاحظة امتلاك الانزيم في خطوة التشبع بكبريتات الامونيوم بنسبة 30\% فعالية نوعية مقدار ها 1100 وحدة/

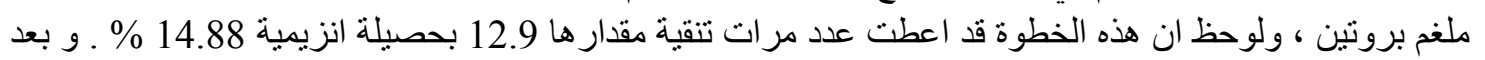

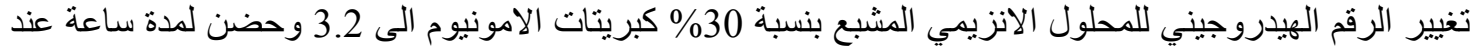

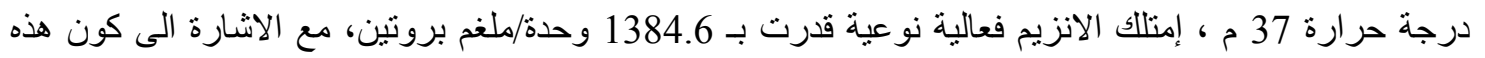

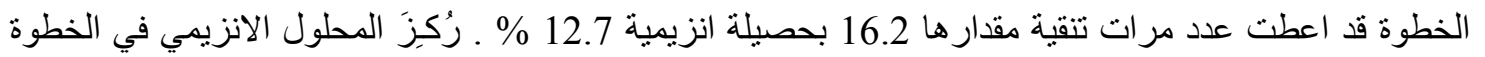

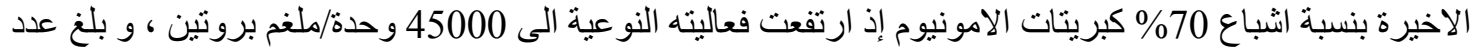

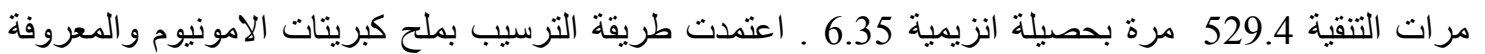

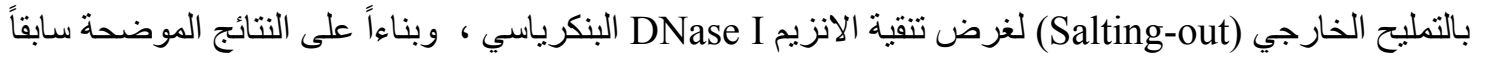

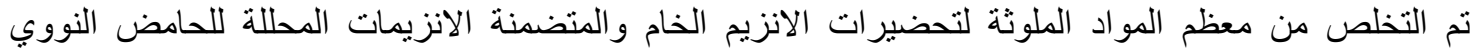

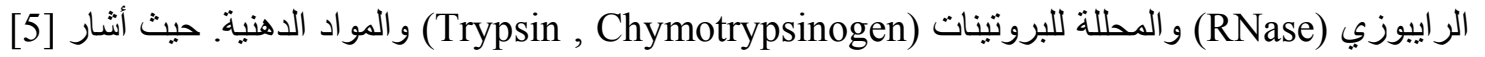

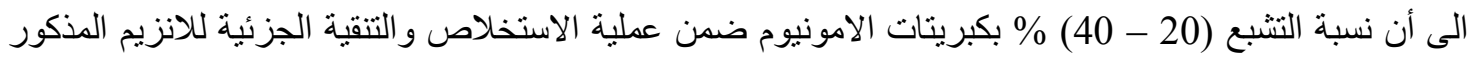

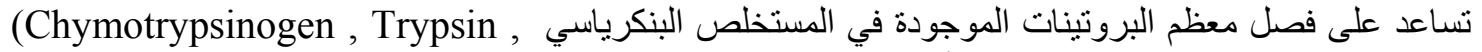
عن البنكرياسي بصورة نقية جزئياً يتم

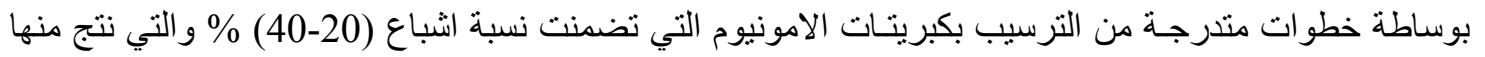

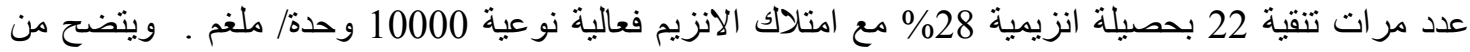

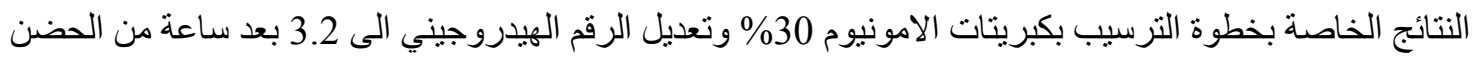

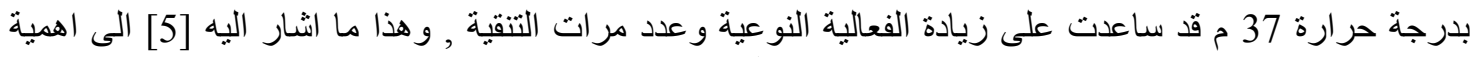
حضن المستخلص الانزيمي في الظروف المذكورة سابقاً يؤدي الى التمسيخ الانتقائي Selective Denaturation

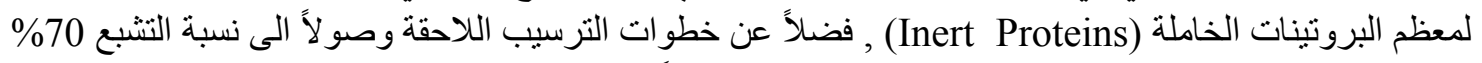

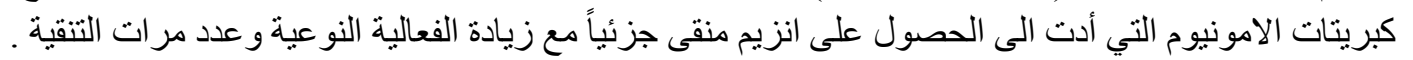

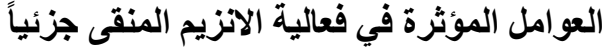

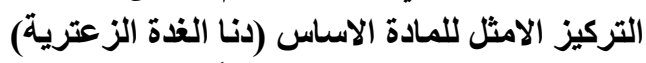

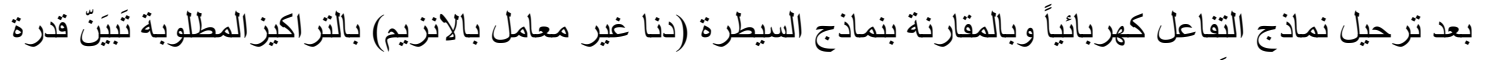

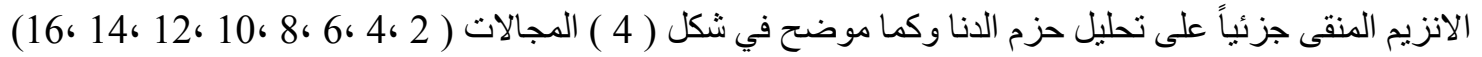




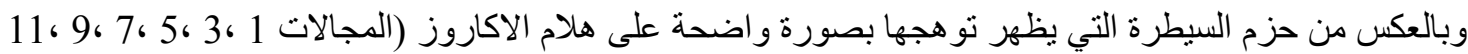

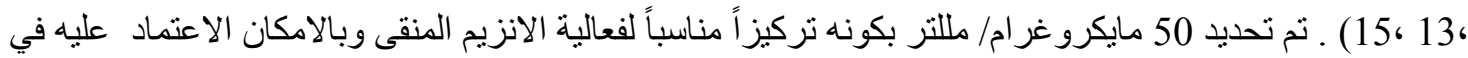

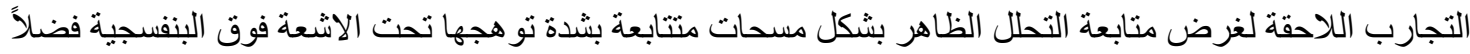

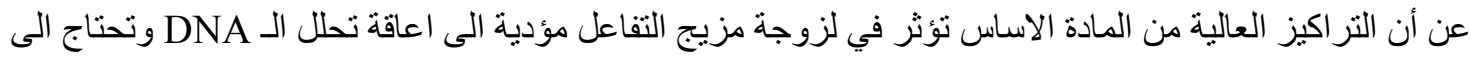

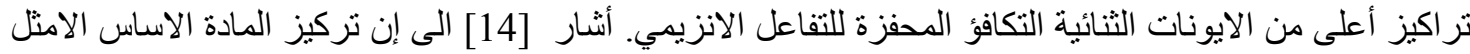

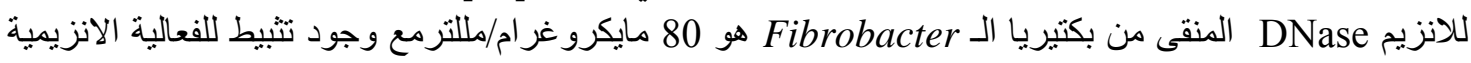

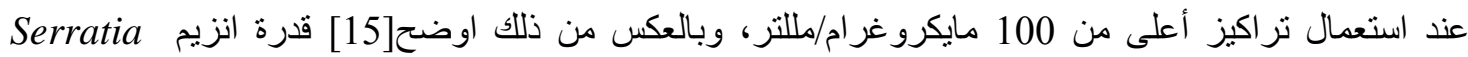
nuclease

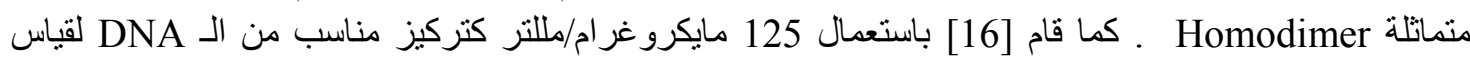

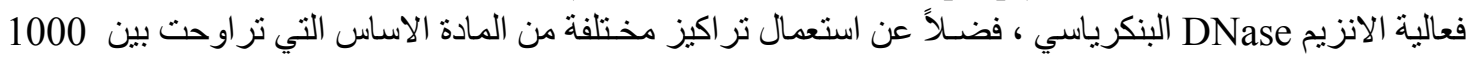

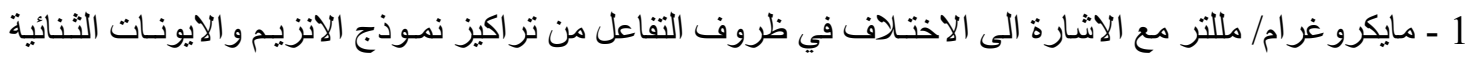

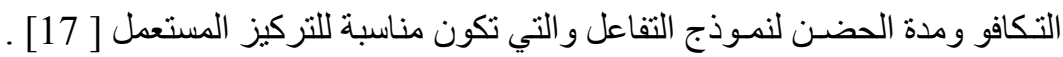

المجال رقم (1 ) : نموذج الدنا بتركيز 500 مايكروغرام / مللتر غير معامل بالانزيم .

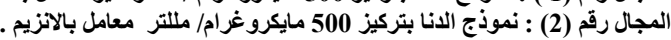

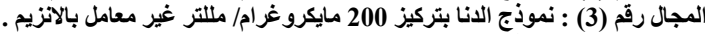

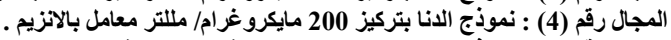

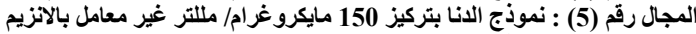

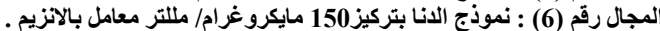

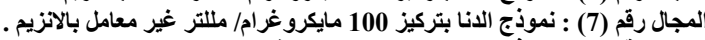

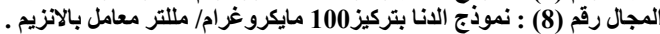

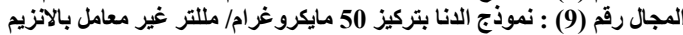

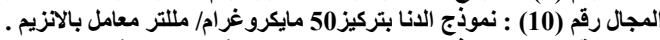

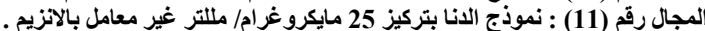

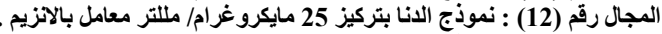

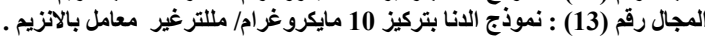

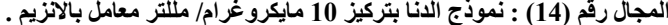

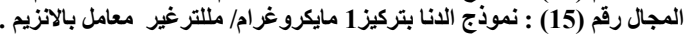

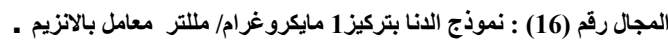

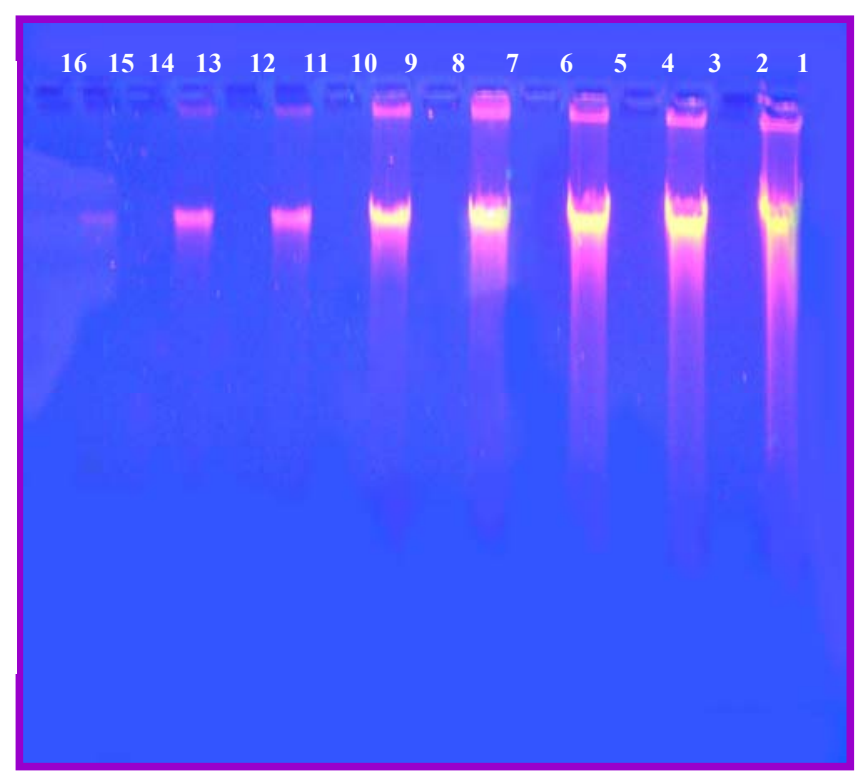

شكل ( 4 ): الترحيل الكهربائي لنواتج تفاعل الانزيم المنقى جزئيا مع المادة الاساس لتحديد التركيز الامثل لها على هلام الاكاروز بتركيز \% 0 8 8

\section{زمن التفاعل الافضل للانزيم DNase I البنكرياسي المنقى جزئياً}

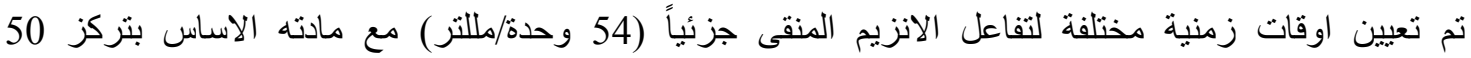

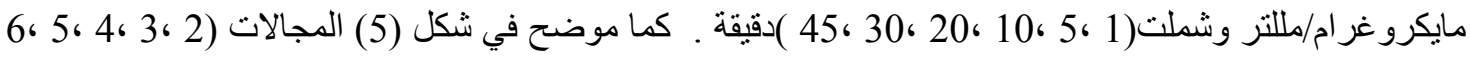

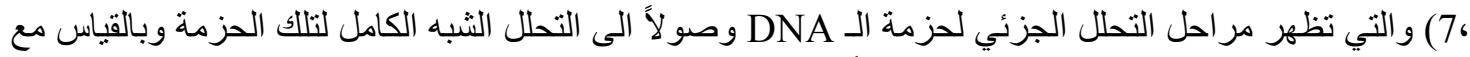

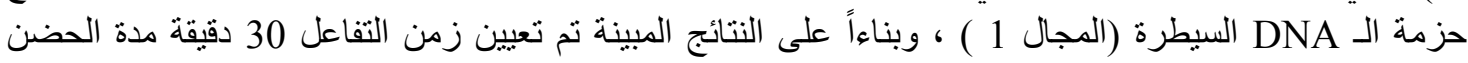

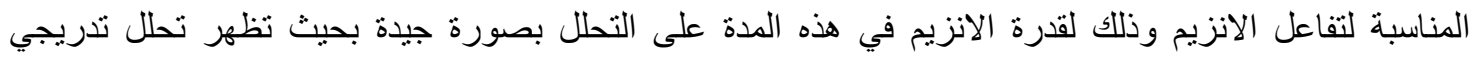

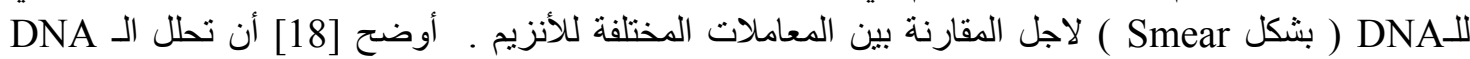

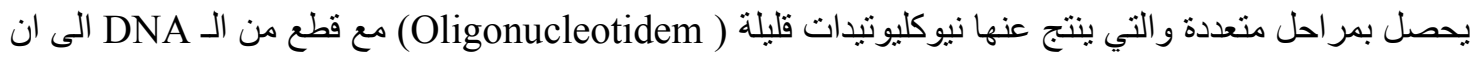

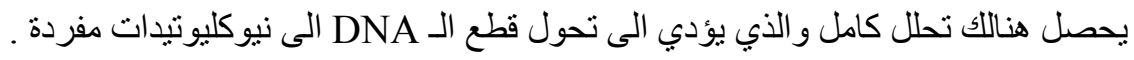


المجال رقم (1) : نموذج الانا غير معامل بالانزيم بتركيز 50 مايكروغرام/مللتر

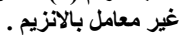

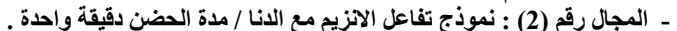

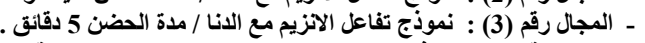

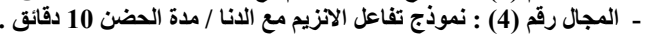

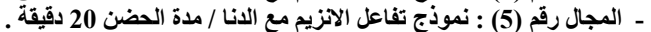

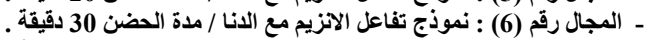

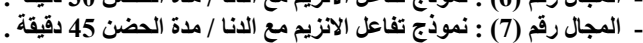

شكل ( 5 ) : الترحيل الكهربائي لنو اتج تفاعل الانزيم المنقى جزئيا مع المادة الاساس(دنا الغذة الزعترية) باوقات حضن مختلفة على هلام الاكاروز بتركيز

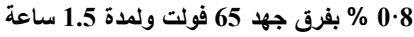

التركيز الامثل للانزيم DNase I المينقى جزئياً

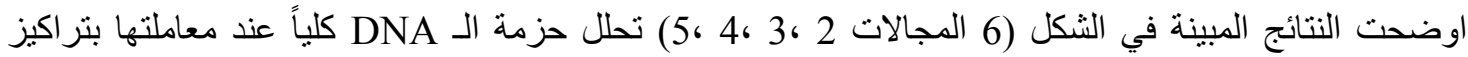

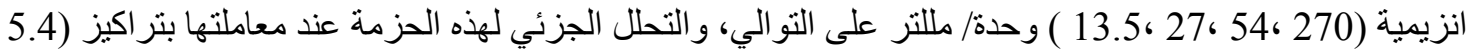

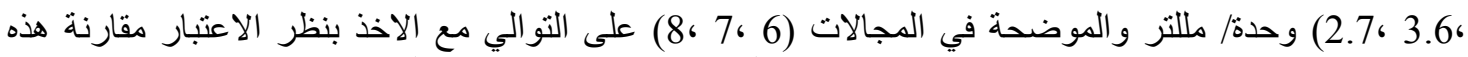

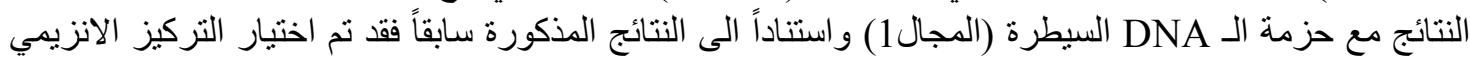

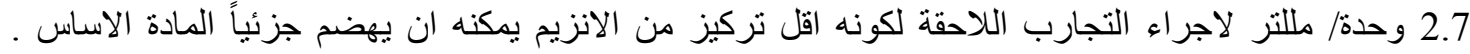

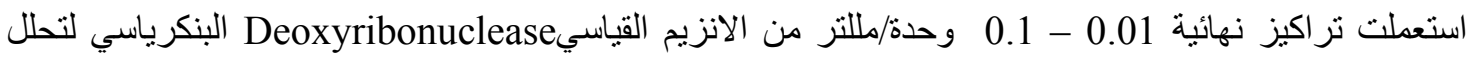

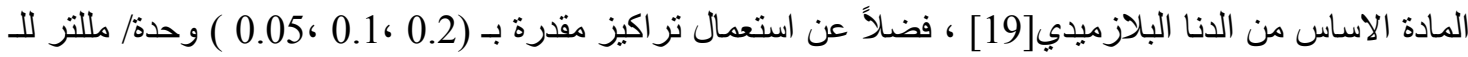
Fibrobacter DNase A

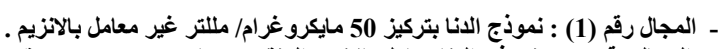

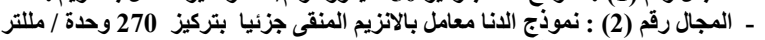

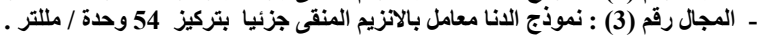

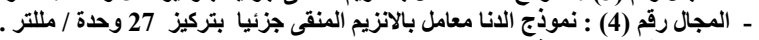

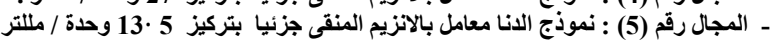

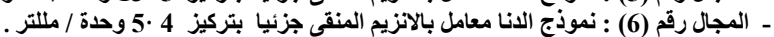

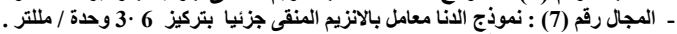

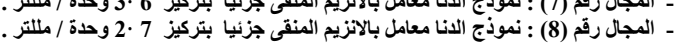

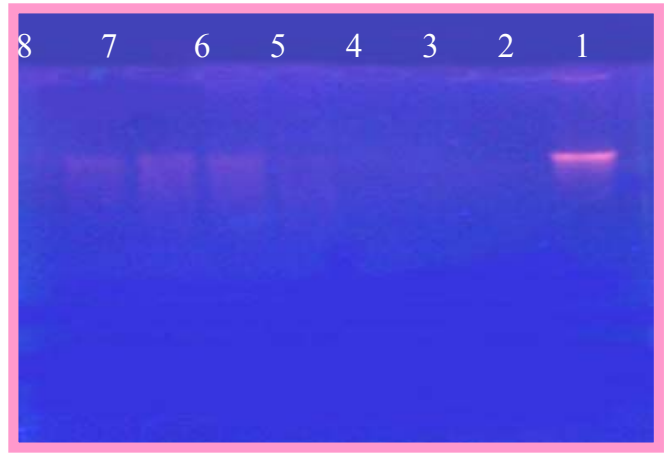

شكل ( 6 ) :تفاعل الانزيم مع المادة الاساس(دنا الغدة الزعترية) لتحليد التركيز الامثل من الانزيم المنقى جزئيا على هلام الاكاروز

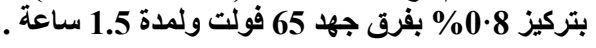

الرقم الهيروجيني الامثل للفعالية

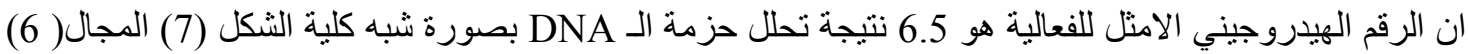
وبالعكس من حزمة السيطرة (المجال 5) مع وجود فعالية قليلة للانزيم في الرقم الهيدرودئل

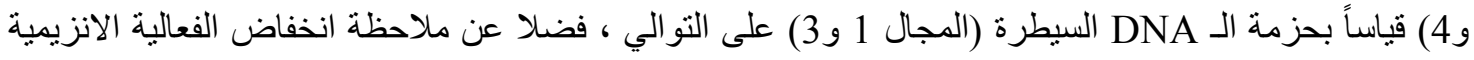

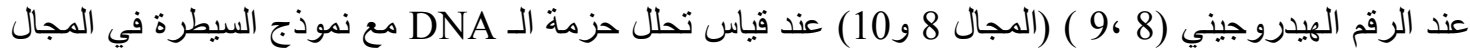

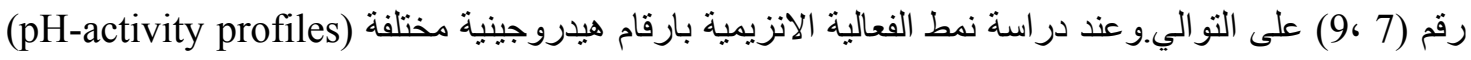


تبين ان منحنى الفعالية كان اقرب الى الثكل الجرسي (Bell-shaped curves) مع امتلاكه اعلى فعالية عند الرقم

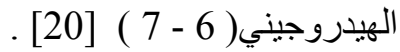

\footnotetext{
المجال رقم (1) : دنا الغدة الزعترية برقم هيدروجيني 4 غير المعامل بالانزيم .

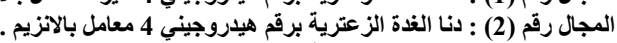

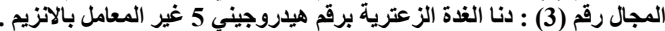

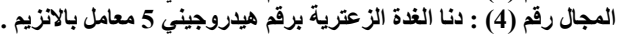

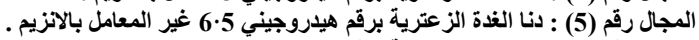

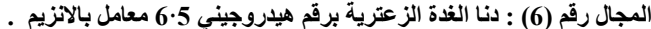

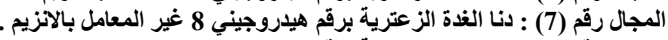

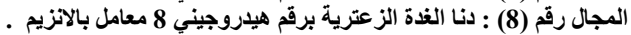

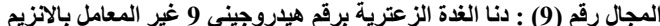
المجال رقم (10) : د دنا الغدة الزعترية برقم هيدروجيني 9 معامل بالانزيم .
}

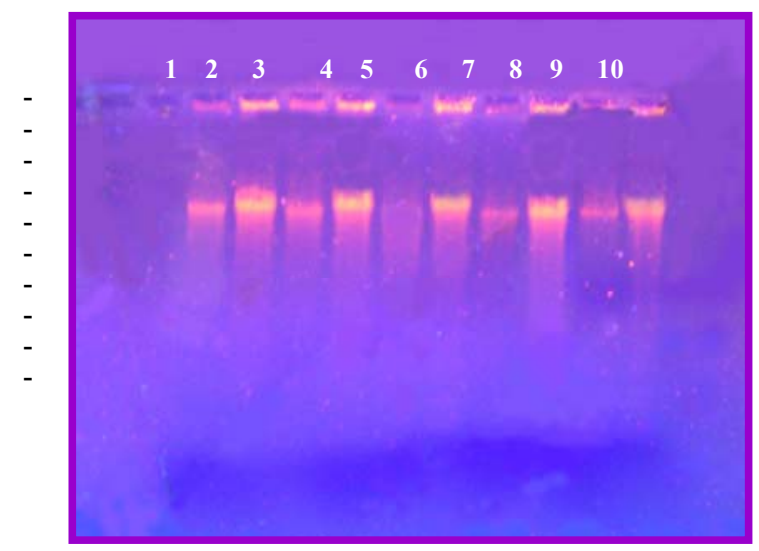

شكل (7): تفاعل الانزيم مع المادة الاساس(دنا الذدة الزعترية) لتحديد الرقم الهيدروجيني الامثلل لفعالية الانزيم على هلام الاكاروز بتركيز 0.8 \% بفرق جها 65 فولت ولمدة 1.5 ساعة .

الرقم الهيدروجيني الامثل للثباتية

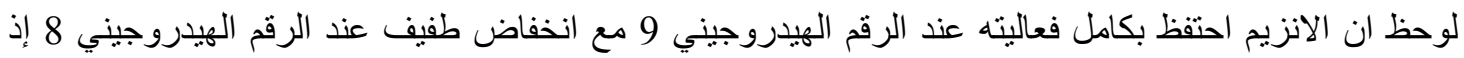

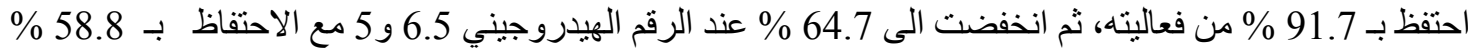

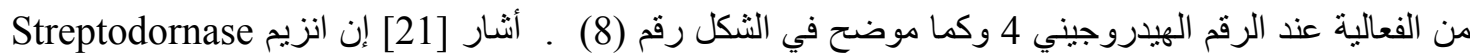

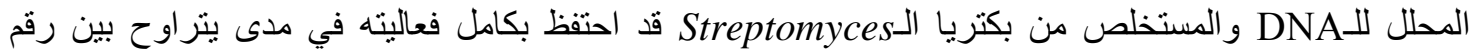
هيدروجيني 8 - 9 مع انخفاض في الفعالية المنتقية للانزيم عند الارقام الهيدروجينية الحامضية والقاعدية المنطرفة .

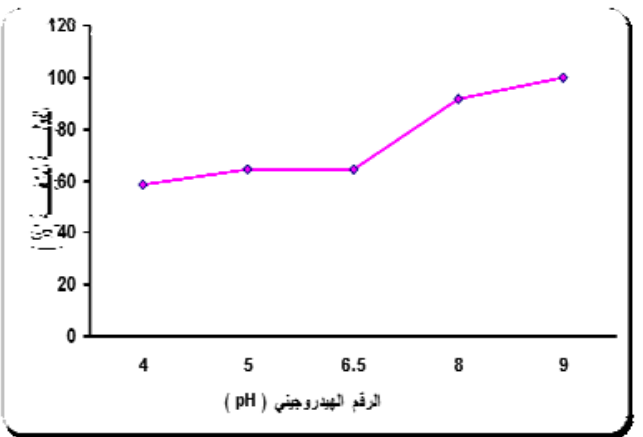

شكل (8 ) ) : تأثير قيم مختلفة من الرقم الهيدروجيني (4 - 9 ) في ثباتية الانزيم DNase I البنكرياسي

الارجة الحرارية المثلى لفعالية الانزيم

كما موضح في شكل (9) اظهرت النتائج إن اقصى فعالية للانزيم كانت عند درجة حرارة الناة 50 م م (المجال 5)، فضلا

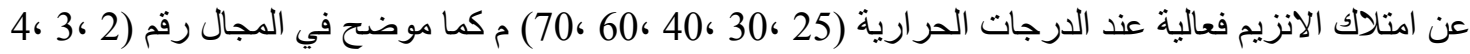

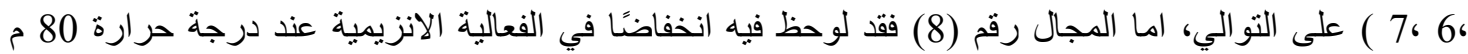

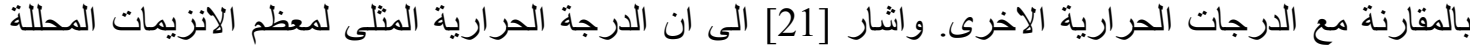

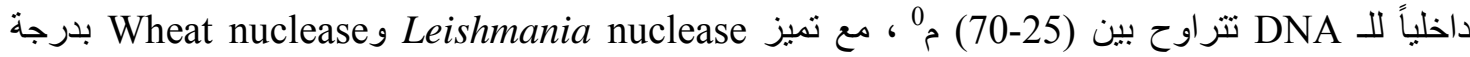

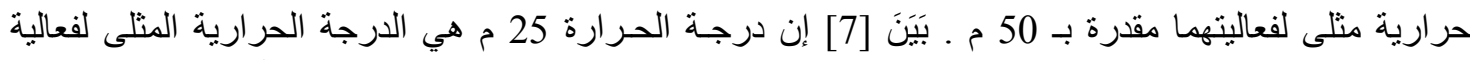
Fibrobacter DNase A

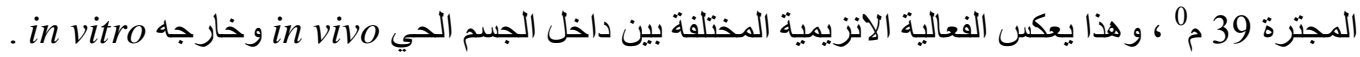


المجال رقم (1) : دنا الغدة الزعترية بتركيز 50 مايكروغرام/مللتر غير

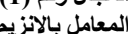

المجال رقم (2) : التفاعل الانزيمي بلرجة حرارة 25 م م.

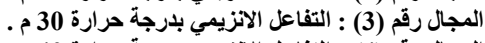

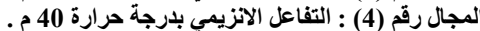

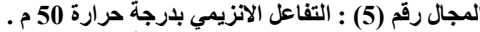

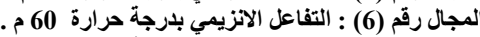

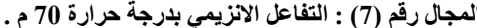

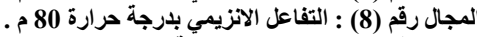

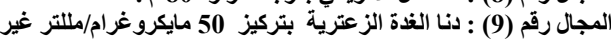
المعامل بالانزيم

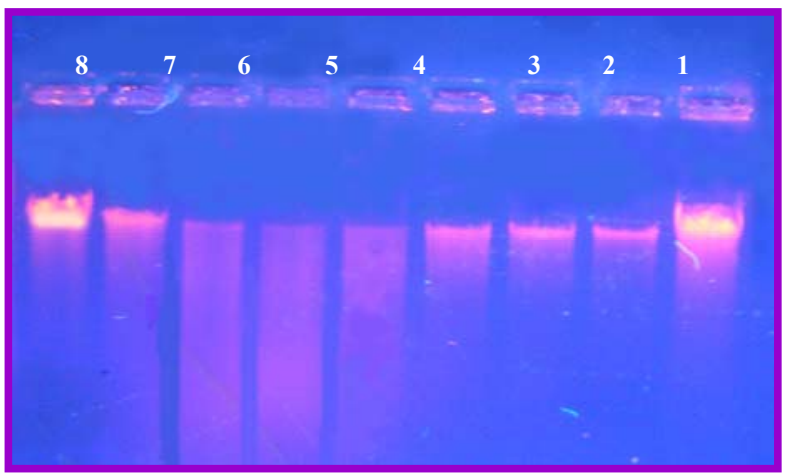

شكل (9): تفاعل الانزيم مع المادة الاساس (دنا الغدة الزعترية ) لتعيين الارجة الحرارية المثلى لفعالية الانزيم المنقى جزئيا على ولى

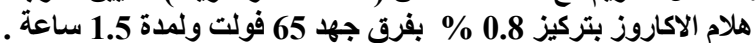

تأثير بعض الاملاح في فعالية الانزيم DNaseI

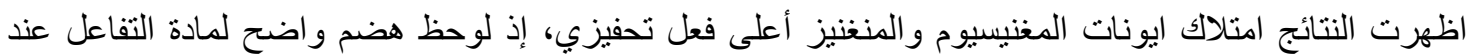

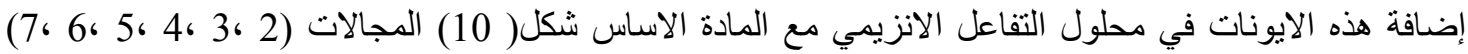

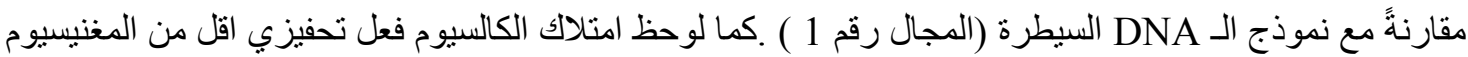

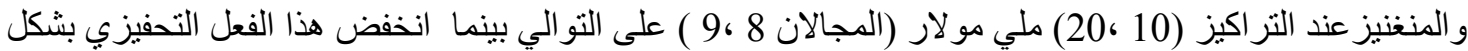

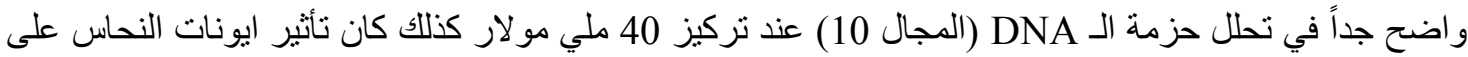

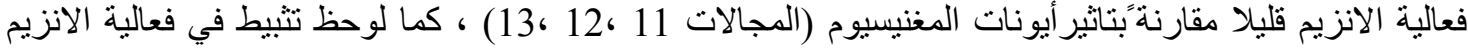

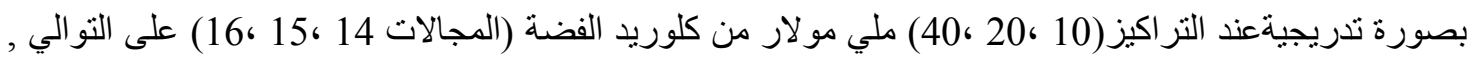

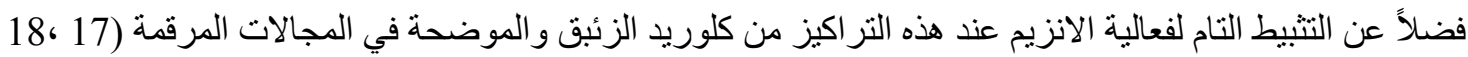

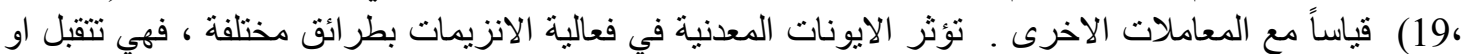

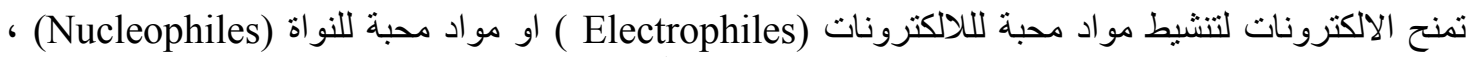
ويتم ذلك حتى في الدحاليل المتعادلة كما يمكن ان تقوم هي ايضاً بوظيفة تلك المواد نفاد نفسها، فضلاً عن ذللك تقوم بربط

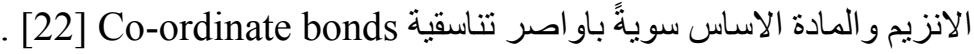

\footnotetext{
ـ المجال رقم (1) : دنا الغدة الزعترية بتركيز 50 مايكروغرام/ملتلتر غير المعامل بالانزيم .

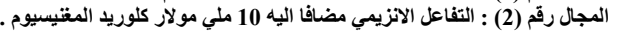

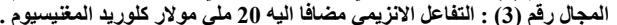

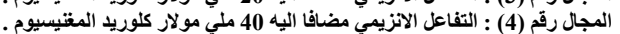

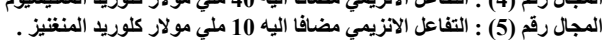

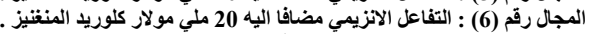

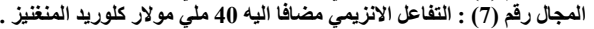

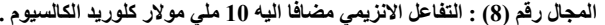

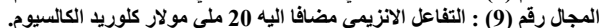



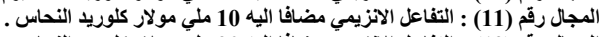

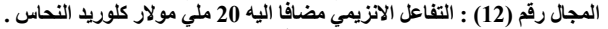

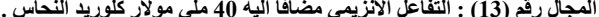
- المجال رقم (14) : التفاعل الانزيمي مضافا اليه 10 ملي مولار كلوريد الفضة .
}

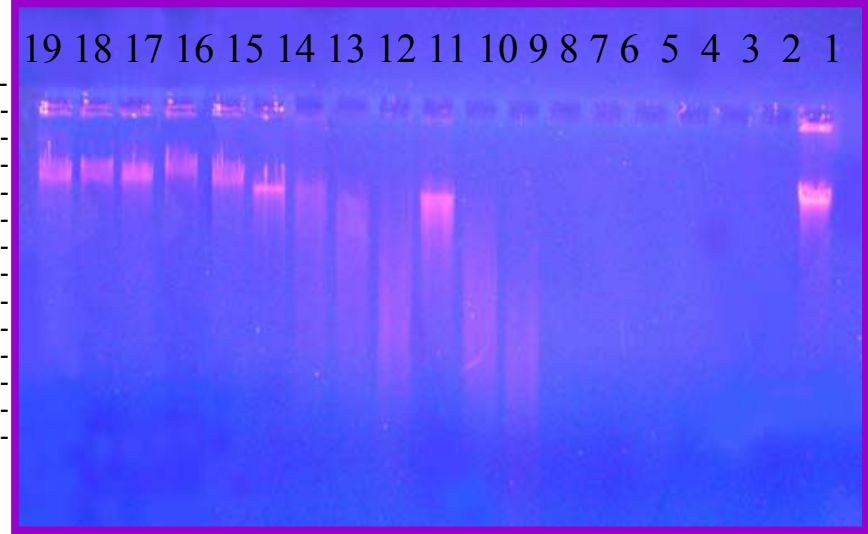

شكل (10): الترحيل الكهربائي لنواتج تفاعل الانزيم مع المادة الاساس (دنا الغدة الزعترية ) بوجود تراكيزمختلفة لمحاليل بعض بوض

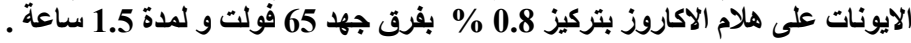

تأثير بعض المركبات الكيميائية على فعالية الانزيم

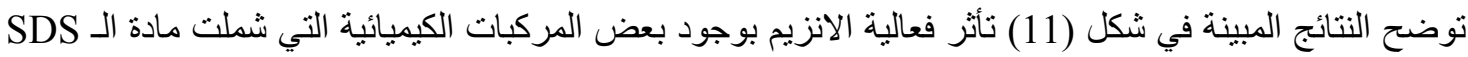

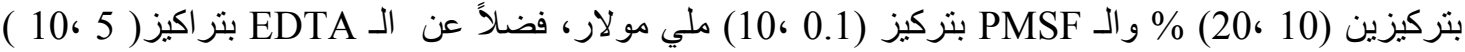




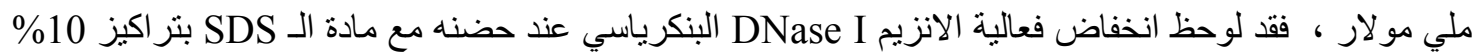

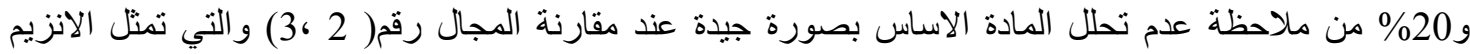

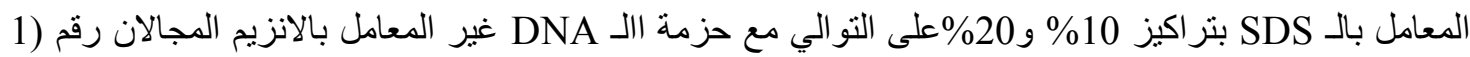

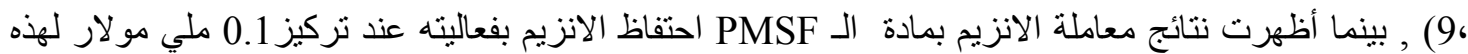

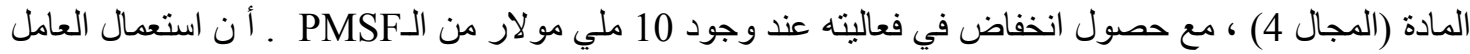

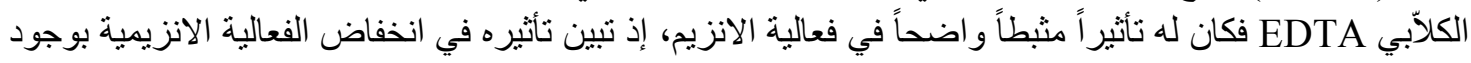

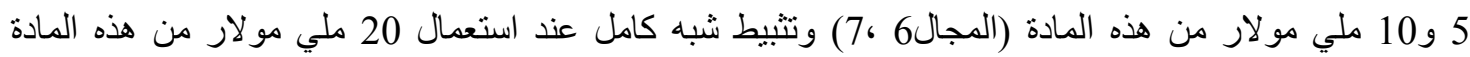

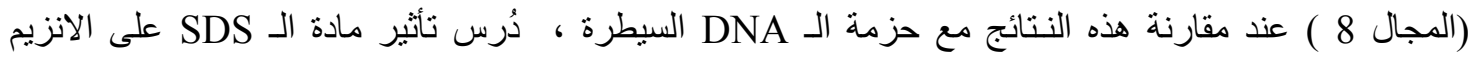
البنكرياسي من قبل الباحث [23 DNase I

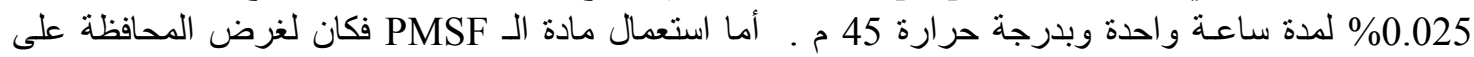

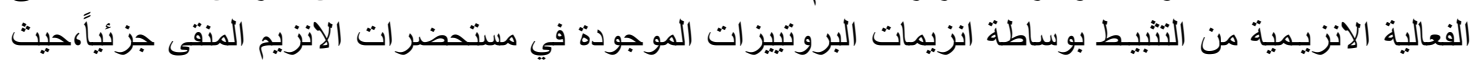

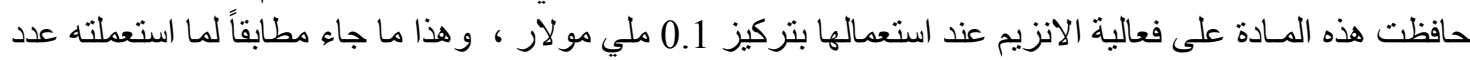

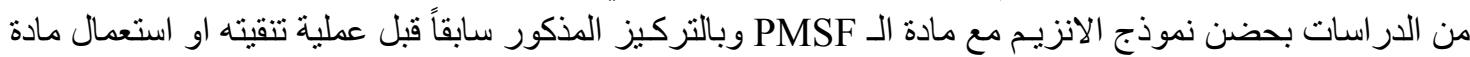

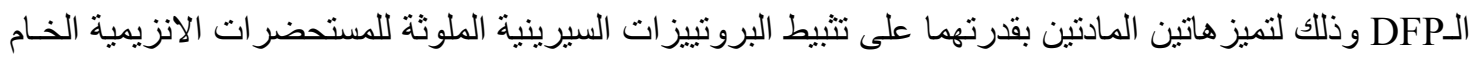

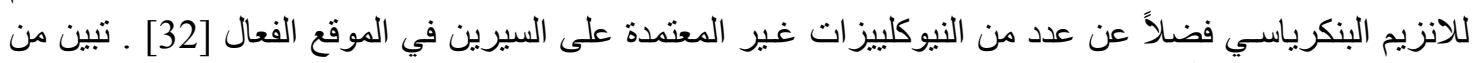

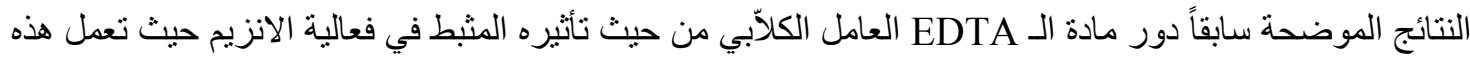

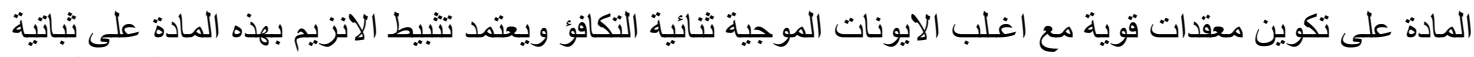

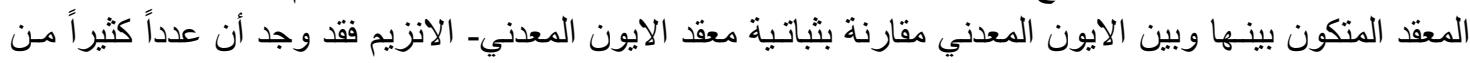

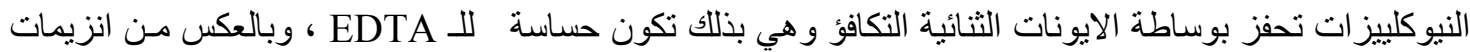
التي تحتفظ بكامل فعاليتها عند المعاملة بـ 5 ملي مولار EGNaseII

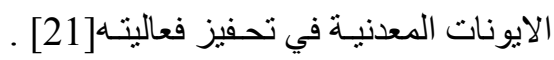

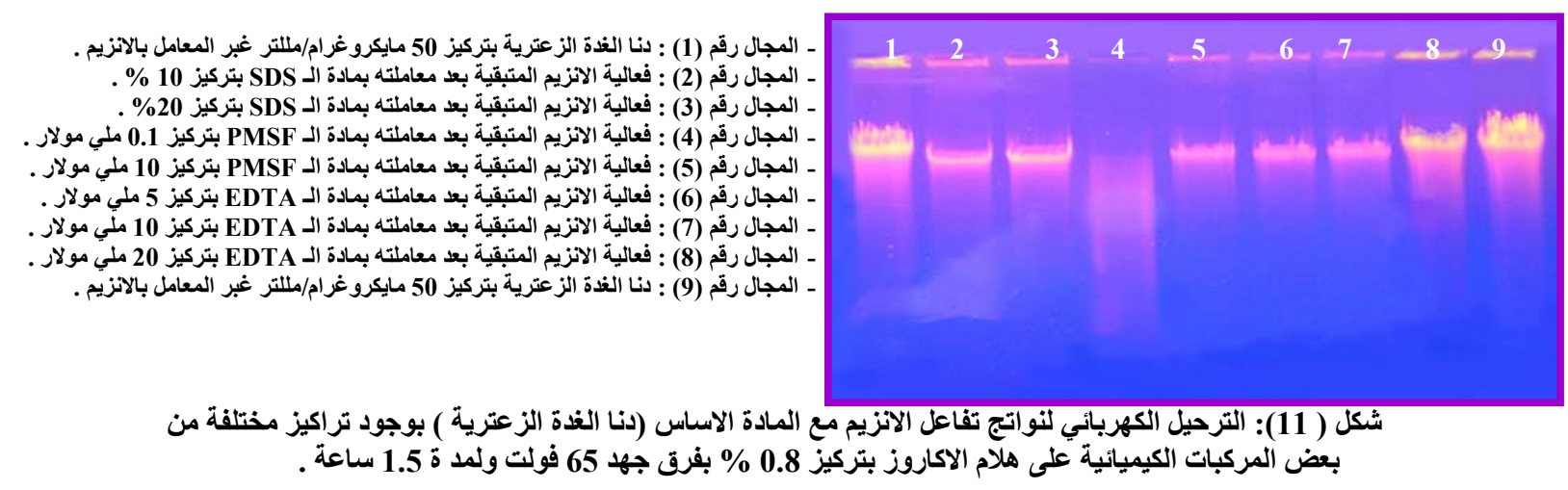

تأثير مادة اليورياو 2 - مركبتو ايثانول

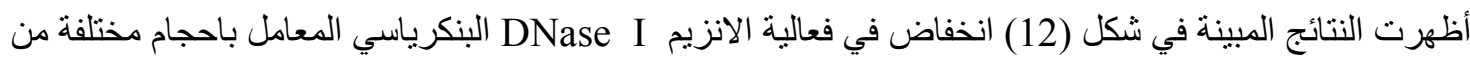

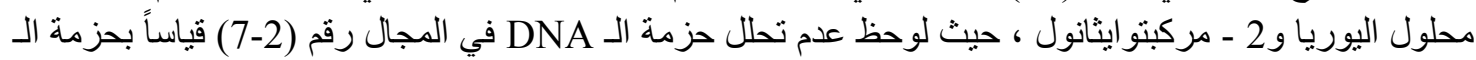

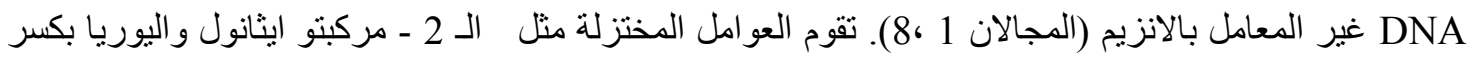

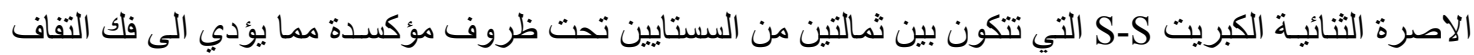

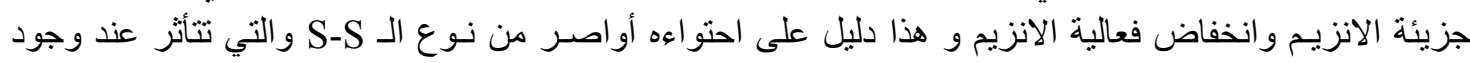

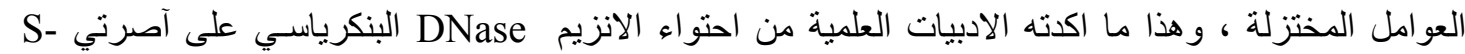

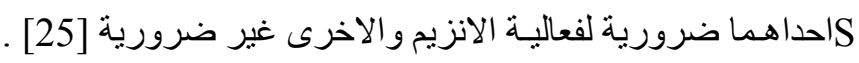


ـ المجال رقم (1) : دنا الغدة الزعترية بتركيز 50 مايكروغرام/ مللتر غير المعامل بالانزيم .

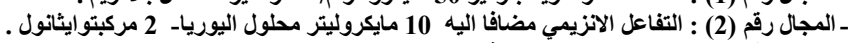

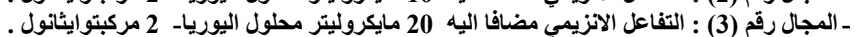

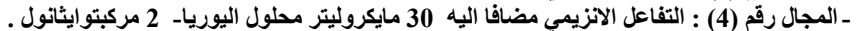

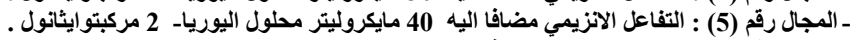

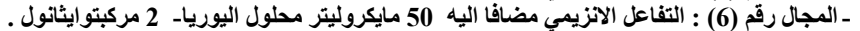

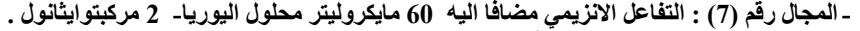

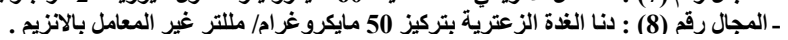

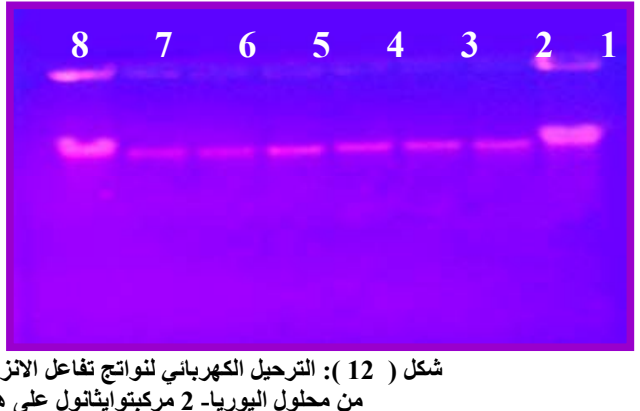

\section{Referenses :}

1. Carpenter, E.P.; Corbett, A.; Thomson, H.; Adacha, J.; Jensen, K.; Bergeron. J.; Kasampalid. I.; Exley, R.; Winterbotham, M.; Tang, C.; Baldwin, G. and Freemont, P. (2007). AP endonuclease paralogues with distinct activities in DNA repair and bacterial pathogenesis. EMBO J. 26: 1363-1372.

2. Begam,M. ; Narwal,S. ; Roy,S. ; Kumer,S. ; Lodha,L. and Kapoor ,H.C.(2006).Anantiviral protein having deoxyribonuclease and ribonuclease activity from leaves of the post-flowering stage of Celosia cristata .Biochem.(Moscow).71:s44-s48.

3. Chen, W.J. and Liao, T.H. (2006). Structure and Function of Bovine Pancreatic Deoxyribonuclease I. Protein and Peptide left. 13 (5): 1-7

4. Chen, W.J.; Lo, T.; Lai, Y.S.; Huang, P.T.; Lin, C.C. and Liao, T.H.(2007 a).Construction and Characterization of bifunctional enzyme with Deoxyribonuclease I and thioredoxin- like activities. Biochem. Biophys. Res. Commun. 356: $750-755$.

5. Kunitz, M. (1950 a). Crystalline Deoxyribonuclease I. II-Digestion of thymus nucleic acid and the kinetics of the reaction.J.Gen.Physiol.33:363-377

6. Kay,E.R. ; Simmons,N. and Dounce,A. (1952). An Improved preparation of deoxyribonucleate . J.Am.Chem.Soci.74:1724-1726.

7. Lee,S.F. ; Forsberg,C.W. and Gibbins,A. (1992). TypeII DNA restriction modification system and an endonuclease from the rminal bacterium Fibrobacter succinogenes S85. J.Bacteriol. 174 (16) : 5275 - 5283.

8. Whitaker, C. Falk, K. and Sanclez, H. (1980). Detection of the proteins by absolute method. Anal. Biochem.109: 156 - 160 .

9. Grestfield,A.M.;Moore,S.and Stein,W.H. Reduction of the deoxyribonuclrase by reducing agent .J.Biol.Chem. (1963) $238: 622-630$.

10. Doherty,A.J.;Worrall,A.F. andConnolly,B.A.(1995).The role of Aginine 41 and Tyrosine 76 in the coupling of DNA recognition tophosphodiester bond cleavage by DNase I :A study using site-directed mutagenesis .J.Mol.Biol.251:366-377.

11. Takeshita, H.; Mogi, K; Yasuda, T.; Nakajima, T. Nakashima, Y.; Mori, S.; Hoshino, $\mathrm{T}$ and Kishi, K. (2000). Mammalian Deoxyribonuclease I are classified into three 
types: Pancrease, Parotid, and Panereas - Parotid (Mixed), based on differences in their Tissue concentrations. Biochem. Biophys. Res. Commun. 269: $481-484$.

12. Lu, S.; Shih,C.H. and Liao, T.H. (2003) Expression of DNase I in Rat Parotid gland and small intestine is regulated by starvation and refeeding. J. Nutrition. 133: 71-74

13. Kuntiz,M.(1950b).Crystalline Deoxyribonuclease I :Isolation and general properties .J.Gen.physiol .33:349-362

14. Maclellan, S. R. (1999). Purification and characterization of DNase A, The major endonuclease of Fibrobacter succinogenes S85.M.Sc.thesis.The faculty of Gradute studies/Guelph Universites.

15. Friedhoff, P.; Meiss, G.; Kolmess, B.; Pieper, U.; Gimadutdinow, O.; Urbanke, C. and Pingound, A. (1996). Kinetic analysis of the cleavage of natural and Synthetic Subsrates by the Serratia nuclease. Eur. J. Biochem. 241: 572-520.

16. Liao, T.H. and Hsieh, J.C. (1988). Hydrolysis of P-nitro Phenylphosphonate Catalysed by bovine pancreatic Deoxyribonuclease. Biochem. J. 255: 781-787.

17. Nadano,D.; Yasuda,T.and Kishi,K.(1993).Measurement of deoxyribonucleae I activity in human tissue and body fluids by Single Radial Enzyme Diffusion method .Clinc. Chem. 39 (3) : $448-452$.

18. Counis, M.F.; Chaudun, E.; Arruti, C.; Oliver.; Sanwal, M.; Courtois, Y. and Torriglia, A. (1998). Analysis of nuclear degredation during cell differentiation. Cell Death Differ. 5: 251-261.

19. Sasaki,Y.;Miyoshi,D.and Sugimoto,N.(2007).Regulation of DNA nuclease by molecular crowding .Nucleic Acids Res.445:1-8 .

20. Chen, W.J.; Lai, P.J.; Lai, Y.S.; Hsang, P.T.; Lin,C.C. and Liao, T.H.(2007 b).Probing the catalytic mechanism of Bovine pancreatic Deoxyribonuclease I by Chemical rescue. Biochem. Biophys. Res. Commun. 352: 689-696.

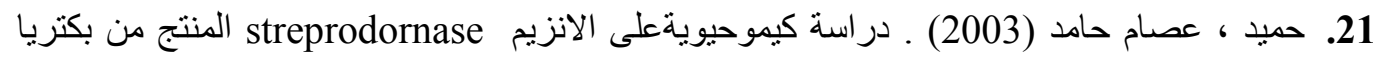
. رسالة ماجستير. التقنيات الاحيائية / جامعة بغداد. . pyogenes Streptococcus

22. Rangarajan,E.S. and Shanker,V.(2001).Sugar non-Specific endonuclease .FEMS Microbiol rev.25:583-613.

23. Palmer,T.(1985).Understanding enzymes $2^{\text {nd }}$ ed .Ellis Honwood limited .

24. Shiokawa, D.; Ohyama, H.; Yamada, T. and Tanuma, S-I. (1997). Purification and Properties of DNase $\delta$ from apoptotic rat thymocytes. Biochem. J. 326: 675-681.

25. Baker, K.P.; Baron, W.F.; Henzel, W.J. and Spancer, S.A. (1998). Molecular Cloning and Characterization of human and murine DNase II. Gene. 215: 281-289. 